\title{
Value Concept and Economic Surplus: A Suggested Reformulation
}

\author{
Truong Hong Trinh \\ University of Economics, The University of Danang, Danang City, Vietnam \\ Email: trinh.th@due.edu.vn
}

How to cite this paper: Trinh, T.H. (2019) Value Concept and Economic Surplus: A Suggested Reformulation. Theoretical Economics Letters, 9, 1920-1937. https://doi.org/10.4236/tel.2019.96122

Received: June 5, 2019

Accepted: August 19, 2019

Published: August 22, 2019

Copyright (C 2019 by author(s) and Scientific Research Publishing Inc. This work is licensed under the Creative Commons Attribution International License (CC BY 4.0).

http://creativecommons.org/licenses/by/4.0/

\begin{abstract}
Value concept and economic surplus are very important in explaining value creation and value distribution in the economy. From the value creation perspective, this paper explores the value concept to understand the relationship between price and value for a commodity in the market, in which value is created in the consumption, and price has a role in value distribution between firms and customers. Theoretical models are developed to identify the supply functions on the logic of maximizing behaviors in the market. The numerical experiments are used to conduct the value balance between the firm and the customer, the value balance is also a necessary condition for market equilibrium including price equilibrium and value equilibrium. The study result reveals that economic surplus is reformulated under market equilibrium, but it is measured upon the maximizing behaviors of firms and customers in the market. The paper contributes to the development of value theory that provides a clear understanding of market behavior and welfare analysis in the economy.
\end{abstract}

\section{Keywords}

Value Concept, Value Creation, Market Equilibrium, Surplus Concept, Economic Welfare

\section{Introduction}

The value concept has a crucial role in economics, in which the theories of value are formed upon the distinct views of price and value. Classical economists held that the value of a commodity comes from production, in which input factors and production conditions are the base of the value [1] [2] [3]. Neoclassical economists held that the value depends on its utility that comes from exchange and consumption [4] [5] [6] [7]. Later, Marshall [8] developed a new tool of 
marginalists in order to explain price in terms of supply and demand, in which the price and output of a commodity are determined by both supply and demand. Although many economists attempted to explain value derived from production or consumption, there is still not clearer understanding of how the value it is. The big challenge is how to measure the value of a commodity and distribute the value between the firm and the customer in the market.

In economic literature, the economic surplus is not only a very important concept in economic theory, but also a crucial base in formulation of economic policies. Classical economists addressed the surplus concept under the terms of surplus value [9] and economic surplus [10], in which the surplus concepts are defined upon production process. Marx's surplus value is defined as the new value created by workers in excess of their own labor cost. Neoclassical economists [8] [11] addressed the surplus concepts including customer surplus and producer surplus, in which the surplus concepts are defined upon market exchange. Marshallian surplus and Hicksian surplus have been criticized for unrealistic and questionable assumptions that are unable to explain the underlying relationship between value added and economic welfare.

To deal with these challenges, the value concept should be redefined upon the new theory of value which not only conducts the value balance between the firm and the customer in value creation systems, but also explains market equilibrium including both price equilibrium and value equilibrium. While market equilibrium is the base to define surplus concept, the relationship between value balance and market equilibrium is the key to explain value added and economic welfare. In addition, marginal analysis is used to identify supply curves under the logic of maximizing behaviors, in which the marginal decision rule allows to reformulate customer surplus and producer surplus in the market. For the purpose of the research, the theoretical models are developed for the suggested reformulation on the value concept and economic surplus.

\section{Value Concept}

The value concept has been discussed and debated since Aristotle, 4th century BC [12], who first distinguished between two notions of value-in-use and value-in-exchange; he also developed a theory related to the term value, in which value is driven by certain needs that creates the basis of exchange. Value-in-use was recognized as a collection of substances or things and qualities associated with these collections. Value-in-exchange was considered as the quantity of a substance that could be commensurable value of all things [13]. The value concept has been embedded in the foundations of economics that reflect different ways of thinking about market exchange and value creation.

Classical economics relies on the labor theory of value, which is an objective theory of value. It held that the value of the good comes from, or is based on, the amount of labor spent producing that good or gone into bringing it to market for exchange (value-in-exchange). This classical approach included the works of 
Adam Smith [1] and David Ricardo [2]. Neoclassical economics relies on the utility theory of value, which is a subjective theory of value. It held that utility is measure of value. This stems from a subjective valuation of worth of the good by an economic agent (value-in-use). This neoclassical approach intended to conceptualize utility and construct a theory of price in keeping with the utilitarianism of Jeremy Bentham [4] and Jules Dupuit [5]. Later, William Jevons [6] and Carl Menger [7] developed a tool of marginal analysis that contributes significantly to "marginal revolution" in the early 1870s.

In recent literature, economists have attempted to define the value concept to explain value creation and value capture in marketing and operations management. Value is something which is perceived and evaluated at the time of consumption [14] [15] [16] [17]. There is a common understanding that value is created in the users' processes as value-in-use [18] [19]. Since value is more appreciate guide to well-being than utility, should economists use the law of diminishing marginal utility to explain demand curve [19]. Thus, the value concept needs to redefine and theory of value should be constructed upon a law of diminishing marginal value. Trinh [20] introduces a new paradigm on the value that provides a better understanding of the value concept and market behaviors. Since the utility concept is redefined with the incorporation of value and price [21], the theory of value provides a better explanation on the relationship between price and value under the following utility function.

$$
T U=u \times Q=(v-p) \times Q=T V-T R
$$

where, $u$ is the utility function, depending on value function $(v)$ and price function $(p) . T V, T R$, and $T U$ are total value, total revenue, and total utility, respectively.

From the value creation perspective, the value creation system involves three processes of production, exchange, and consumption as in Figure 1.

In the value creation system, the firm plays a role as value facilitator, in which value foundation is created in the production process with the Cobb Douglas production function that has been conducted with statistically significant parameters

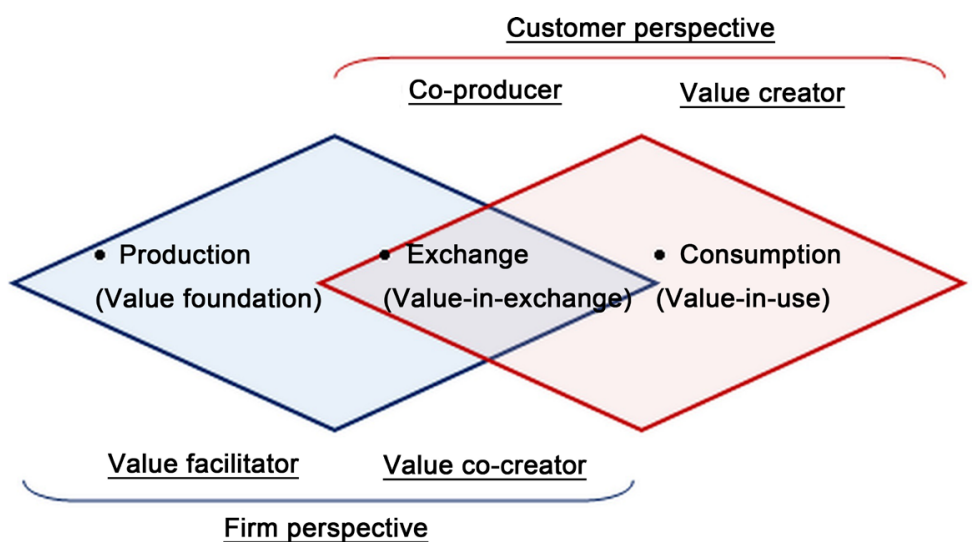

Source: adapted from Grönroos and Voima [22], Trinh [23].

Figure 1. Value creation perspective. 
in various empirical researches of the economy. In addition, the exponent form of the Cobb Douglas production function can be converted to linear production function by taking the logarithm of its Cobb Douglas production function.

$$
Q=f\left(K_{1}, L_{1}\right)=A_{1} \times K_{1}^{\alpha_{1}} \times L_{1}^{\beta_{1}}
$$

where, $Q$ is total output of production. $A_{1}$ is firm's total factor productivity. $K_{1}$ and $L_{1}$ are firm capital and firm labor, respectively. $\alpha_{1}$ and $\beta_{1}$ are the output elasticities of production input factors. The production function yields constant returns to scale with $\alpha_{1}+\beta_{1}=1$; increasing returns to scale with $\alpha_{1}+\beta_{1}>1$; and decreasing returns to scale with $\alpha_{1}+\beta_{1}<1$.

Firm's cost function $\left(T C_{1}\right)$ with two inputs of firm capital $\left(K_{1}\right)$ and firm labor $\left(L_{1}\right)$ is expressed as follows:

$$
T C_{1}=K_{1} \times w_{K_{1}}+L_{1} \times w_{L_{1}}
$$

where, $T C_{1}$ is firm's total cost, $w_{K_{1}}$ and $w_{L_{1}}$ are unit costs of firm capital and firm labor.

Firm's profit function is determined by the following formula.

$$
\Pi=T R-T C_{1}=p \times Q-K_{1} \times w_{K_{1}}-L_{1} \times w_{L_{1}}
$$

where $\Pi$ is firm profit and $T R$ is total revenue $(T R=p \times Q)$.

By using the least-cost combination of production inputs, the values of $K_{1}$ and $L_{1}$ can be found that minimize the Lagrangian $G(\cdot)$.

$$
\begin{gathered}
G(\cdot)=K_{1} \times w_{K_{1}}+L_{1} \times w_{L_{1}}+\lambda_{1}\left(Q-A_{1} \times K_{1}^{\alpha_{1}} \times L_{1}^{\beta_{1}}\right) \\
\frac{\partial G(\cdot)}{\partial K_{1}}=w_{K_{1}}-\frac{\alpha_{1}}{K_{1}} \lambda_{1}\left(A_{1} \times K_{1}^{\alpha_{1}} \times L_{1}^{\beta_{1}}\right)=0 \\
\frac{\partial G(\cdot)}{\partial L_{1}}=w_{L_{1}}-\frac{\beta_{1}}{L_{1}} \lambda_{1}\left(A_{1} \times K_{1}^{\alpha_{1}} \times L_{1}^{\beta_{1}}\right)=0 \\
\frac{\partial G(\cdot)}{\partial \lambda_{1}}=Q-A_{1} \times K_{1}^{\alpha_{1}} \times L_{1}^{\beta_{1}}=0
\end{gathered}
$$

Solving for $K_{1}$ and $L_{1}$ from Equations (6)-(8) yields

$$
\begin{aligned}
& K_{1}=\frac{\alpha_{1}}{w_{K_{1}}} \times Q^{\frac{1}{\alpha_{1}+\beta_{1}}}\left[\left(w_{K_{1}}^{\alpha_{1}} \times w_{L_{1}}^{\beta_{1}}\right) /\left(A_{1} \times \alpha_{1}^{\alpha_{1}} \times \beta_{1}^{\beta_{1}}\right)\right]^{\frac{1}{\alpha_{1}+\beta_{1}}} \\
& L_{1}=\frac{\beta_{1}}{w_{L_{1}}} \times Q^{\frac{1}{\alpha_{1}+\beta_{1}}}\left[\left(w_{K_{1}}^{\alpha_{1}} \times w_{L_{1}}^{\beta_{1}}\right) /\left(A_{1} \times \alpha_{1}^{\alpha_{1}} \times \beta_{1}^{\beta_{1}}\right)\right]^{\frac{1}{\alpha_{1}+\beta_{1}}}
\end{aligned}
$$

By substituting $K_{1}$ and $L_{1}$ into Equation (3), firm's cost function ( $T C_{1}$ ) can be determined as a function of output, depending on input prices and the parameters of the firm's production function as follows:

$$
T C_{1}=\left(\alpha_{1}+\beta_{1}\right) \times Q^{\frac{1}{\alpha_{1}+\beta_{1}}}\left[\left(w_{K_{1}}^{\alpha_{1}} \times w_{L_{1}}^{\beta_{1}}\right) /\left(A_{1} \times \alpha_{1}^{\alpha_{1}} \times \beta_{1}^{\beta_{1}}\right)\right]^{\frac{1}{\alpha_{1}+\beta_{1}}}
$$

Finally, substituting $T C_{1}$ in to Equation (4), firm profit $(\Pi)$ can be determined as a function of output $(Q)$, price $(p)$, and the parameters of the firm's produc- 
tion function as follows:

$$
\Pi=p \times Q-\left(\alpha_{1}+\beta_{1}\right) \times Q^{\frac{1}{\alpha_{1}+\beta_{1}}}\left[\left(w_{K_{1}}^{\alpha_{1}} \times w_{L_{1}}^{\beta_{1}}\right) /\left(A_{1} \times \alpha_{1}^{\alpha_{1}} \times \beta_{1}^{\beta_{1}}\right)\right]^{\frac{1}{\alpha_{1}+\beta_{1}}}
$$

Since the value is created in the consumption process, the customer is always a value creator in such value creation system. Thus, customer capital $\left(K_{2}\right)$ and customer labor $\left(L_{2}\right)$ are added in the consumption function [19] [20] as follows:

$$
Q=f\left(K_{2}, L_{2}\right)=A_{2} \times K_{2}^{\alpha_{2}} \times L_{2}^{\beta_{2}}
$$

where, $Q$ is total output of consumption. $A_{2}$ is customer's total factor productivity. $\alpha_{2}$ and $\beta_{2}$, are the output elasticities of consumption input factors. The consumption function yields constant returns to scale with $\alpha_{2}+\beta_{2}=1$; increasing returns to scale with $\alpha_{2}+\beta_{2}>1$; and decreasing returns to scale with $\alpha_{2}+\beta_{2}<1$.

Customer's cost function $\left(T C_{2}\right)$ with two inputs of customer capital $\left(K_{2}\right)$ and customer labor $\left(L_{2}\right)$ is expressed as follows:

$$
T C_{2}=K_{2} \times w_{K_{2}}+L_{2} \times w_{L_{2}}
$$

where, $T C_{2}$ is customer's total cost, $w_{K_{2}}$ and $w_{L_{2}}$ are unit costs of customer capital and customer labor.

Customer's utility function is determined by the following formula.

$$
U=T U-T C_{2}=(v-p) \times Q-K_{2} \times w_{K_{2}}-L_{2} \times w_{L_{2}}
$$

where, $U$ is customer utility and $T U$ is total utility $(T U=u \times Q=(v-p) \times Q)$.

By using the least-cost combination of consumption inputs, customer's cost function $\left(T C_{2}\right)$ can be determined as a function of output, depending on input prices and the parameters of the customer's consumption function as follows:

$$
T C_{2}=\left(\alpha_{2}+\beta_{2}\right) \times Q^{\frac{1}{\alpha_{2}+\beta_{2}}}\left[\left(w_{K_{2}}^{\alpha_{2}} \times w_{L_{2}}^{\beta_{2}}\right) /\left(A_{2} \times \alpha_{2}^{\alpha_{2}} \times \beta_{2}^{\beta_{2}}\right)\right]^{\frac{1}{\alpha_{2}+\beta_{2}}}
$$

Finally, substituting $T C_{2}$ into Equation (15), customer utility $(U)$ can be determined as a function of output $(Q)$, utility $(u=v-p)$, and the parameters of the customer's consumption function as follows:

$$
U=(v-p) \times Q-\left(\alpha_{2}+\beta_{2}\right) \times Q^{\frac{1}{\alpha_{2}+\beta_{2}}}\left[\left(w_{K_{2}}^{\alpha_{2}} \times w_{L_{2}}^{\beta_{2}}\right) /\left(A_{2} \times \alpha_{2}^{\alpha_{2}} \times \beta_{2}^{\beta_{2}}\right)\right]^{\frac{1}{\alpha_{2}+\beta_{2}}}
$$

From the value creation perspective, the value creation system includes both production process and consumption process, in which value is created in the consumption process. Thus, both firm cost $\left(T C_{1}\right)$ and customer cost $\left(T C_{2}\right)$ have to consider in value creation system. The total cost function (TC) and the net value function $(V)$ are determined as follows:

$$
\begin{array}{rl}
T C & T C_{1}+T C_{2}=K_{1} \times w_{K_{1}}+L_{1} \times w_{L_{1}}+K_{2} \times w_{K_{2}}+L_{2} \times w_{L_{2}} \\
V & =\Pi+U=v \times Q-\left(K_{1} \times w_{K_{1}}+L_{1} \times w_{L_{1}}+K_{2} \times w_{K_{2}}+L_{2} \times w_{L_{2}}\right) \\
& =T V-T C
\end{array}
$$

where, $V$ is net value, $T V$ is total value $(T V=v \times Q)$ and $T C$ is total cost. $w_{K_{1}}$ and $w_{L_{1}}$ are unit costs of firm capital and firm labor. $w_{K_{2}}$ and $w_{L_{2}}$ are unit 
costs of customer capital and customer labor.

The total cost function ( TC) and the net value function $(V)$ can be determined as a function of output $(Q)$, value $(v)$, the parameters of the production function and consumption function as follows:

$$
\begin{aligned}
T C= & \left(\alpha_{1}+\beta_{1}\right) \times Q^{\frac{1}{\alpha_{1}+\beta_{1}}}\left[\left(w_{K_{1}}^{\alpha_{1}} \times w_{L_{1}}^{\beta_{1}}\right) /\left(A_{1} \times \alpha_{1}^{\alpha_{1}} \times \beta_{1}^{\beta_{1}}\right)\right]^{\frac{1}{\alpha_{1}+\beta_{1}}} \\
& +\left(\alpha_{2}+\beta_{2}\right) \times Q^{\frac{1}{\alpha_{2}+\beta_{2}}}\left[\left(w_{K_{2}}^{\alpha_{2}} \times w_{L_{2}}^{\beta_{2}}\right) /\left(A_{2} \times \alpha_{2}^{\alpha_{2}} \times \beta_{2}^{\beta_{2}}\right)\right]^{\frac{1}{\alpha_{2}+\beta_{2}}} \\
V= & v \times Q-\left(\alpha_{1}+\beta_{1}\right) \times Q^{\frac{1}{\alpha_{1}+\beta_{1}}}\left[\left(w_{K_{1}}^{\alpha_{1}} \times w_{L_{1}}^{\beta_{1}}\right) /\left(A_{1} \times \alpha_{1}^{\alpha_{1}} \times \beta_{1}^{\beta_{1}}\right)\right]^{\frac{1}{\alpha_{1}+\beta_{1}}} \\
& -\left(\alpha_{2}+\beta_{2}\right) \times Q^{\frac{1}{\alpha_{2}+\beta_{2}}}\left[\left(w_{K_{2}}^{\alpha_{2}} \times w_{L_{2}}^{\beta_{2}}\right) /\left(A_{2} \times \alpha_{2}^{\alpha_{2}} \times \beta_{2}^{\beta_{2}}\right)\right]^{\frac{1}{\alpha_{2}+\beta_{2}}}
\end{aligned}
$$

\section{Economic Surplus}

The surplus concept becomes a basic concept of welfare economics. This concept was first propounded by Dupuit in 1844 to measure social benefits in public sectors. Dupuit [5] stated that the "maximum sacrifice expressed in money which each consumer would be willing to make in order to acquire an object" provides "the measure of the object's utility". Karl Marx [9] also addressed the value concept under terms of surplus value, he defined the surplus value as a new value in excess of workers' labor costs. In addition, he distinguished the surplus value with the value added, in which the value added is sum of gross wage income and gross profit income.

In Neo-Marxist thought, Baran and Sweezy [10] defined the economic surplus as the difference between what a society produces and the costs of producing. Afred Marshall [8] defined the "economic measure" of a satisfaction as customer surplus which a person would be just willing to pay for any satisfaction rather than go without it. The Marshallian surplus is based upon two basic assumptions: 1) utility can be quantitatively or cardinally measured, and 2) the marginal utility of money remains constant. However, the Marshallian concept of customer surplus has been criticized on the ground of theses dubious assumptions for measuring customer surplus. Hicks and Allen [24] have expressed the view that utility is a subjective and psychic entity, and therefore it cannot be cardinally measured. They also point out that marginal utility of money will rise or fall following the changes in prices of a commodity. Hicks [11] rehabilitated the concept of customer surplus by measuring it with indifference curve technique and inconstancy of the marginal utility of money.

However, neoclassical surplus concept has still two key limitations to apply in welfare analysis of the economy: 1) it is not clear to identify the difference between utility function and demand function, and 2) it does not explain the relationship between value added and economic welfare. To deal with these problems, the surplus concept is built upon the new theory of value that identifies the relationship between price (value in exchange) and value (value in use) in the 
market, where market equilibrium including both price equilibrium $\left(\mathrm{E}_{\mathrm{P}}\right)$ and value equilibrium $\left(\mathrm{E}_{\mathrm{V}}\right)$ as in Figure 2.

Marginal principle is used to identify supply curves and reformulate surplus concepts in the market. The logic of maximizing behavior is always the heart of economic analysis, in which marginal analysis allows firms (or customers) to measure the additional benefits versus its costs related to each economic activity (production or consumption). This marginal analysis can also help firms (or customers) understand whether an activity increase firm profit (or customer utility). Marginal analysis is used to determine the activity levels of production and consumption where marginal benefit is equal to marginal cost. Thus, the marginal decision rule determines the optimal levels in production and consumption in the market.

In the value creation system, the firm seeks to maximize firm profit $\left(\Pi_{\max }\right)$ which is the difference between total revenue $(T R)$ and firm's total cost $\left(T C_{1}\right)$ in production process. The customers seek to maximize customer utility $\left(U_{\max }\right)$ which is the difference between total utility $(T U)$ and customer's total cost $\left(T C_{2}\right)$ in the consumption process.

For simply illustration on graph, price demand $\left(D_{P}\right)$ and price supply $\left(S_{P}\right)$ are assumed as the forms of linear demand and linear supply, but these functions of demand and supply follow the laws of demand and supply respectively. Price demand $\left(D_{P}\right)$ and price supply $\left(S_{P}\right)$ for a commodity are given under the following forms.

Price demand:

$$
p=A_{1}+B_{1} \times Q_{D}
$$

Price supply:

$$
p=A_{2}+B_{2} \times Q_{S}
$$

From the logic of maximizing behavior, the demand function $\left(D_{P}\right)$ is intersected with the supply function $\left(S_{P}\right)$ at the quantity $\left(Q_{E p}\right)$ where the marginal revenue $(M R)$ equals firm's marginal cost $\left(M C_{1}\right)$ as in Figure 3. Thus, marginal

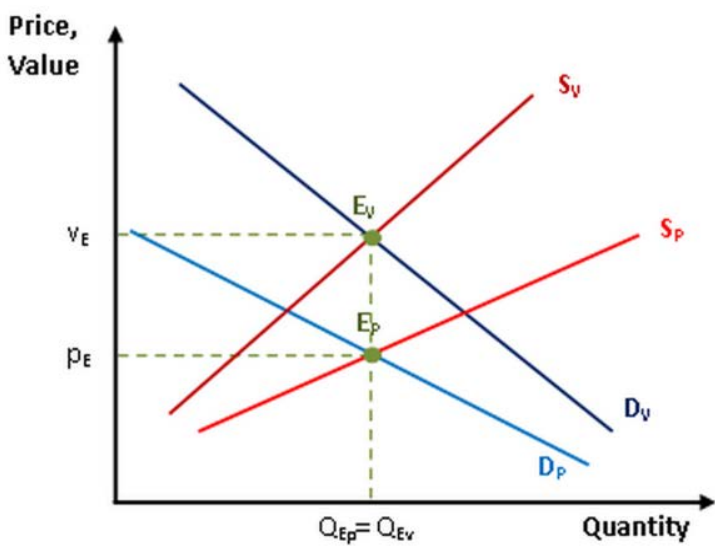

Source: Trinh [19].

Figure 2. Market equilibrium. 
revenue $(M R)$ and firm's marginal cost $\left(M C_{1}\right)$ are determined as follows:

Marginal revenue:

$$
M R=A_{1}+2 B_{1} \times Q
$$

Firm's marginal cost:

$$
M C_{1}=A_{2}+\left(B_{1}+B_{2}\right) \times Q
$$

For profit-maximizing decision, the firm will produce at the quantity $\left(Q_{E P}\right)$ where marginal revenue $(M R)$ equals the firm's marginal cost $\left(M C_{1}\right)$.

Price's equilibrium quantity:

$$
Q_{E p}=\frac{A_{1}-A_{2}}{B_{2}-B_{1}}
$$

The profit-maximizing quantity is also the price's equilibrium quantity $\left(Q_{E p}\right)$ in which the firm will sell at the equilibrium price $\left(p_{E}\right)$ determined on the price demand $\left(D_{P}\right)$, ceteris paribus.

Equilibrium price:

$$
p_{E}=\frac{A_{1} \times B_{2}-A_{2} \times B_{1}}{B_{2}-B_{1}}
$$

Figure 3 shows the relationship between firm profit and producer surplus. Firm profit (the maximum value added to the firm) is the triangular area of $A_{1} J A_{2}$. This firm profit is exactly equal to producer surplus (the triangular area of $\left.A_{1} E_{p} A_{2}\right)$ whenever changes in price demand $\left(D_{P}\right)$ or firm's marginal cost $\left(M C_{1}\right)$. Firm profit $(I I)$ and producer surplus $(P S)$ are determined as follows:

Firm profit:

$$
\Pi=\int_{0}^{Q_{E p}} M R \mathrm{~d} Q-\int_{0}^{Q_{E p}} M C_{1} \mathrm{~d} Q=\frac{A_{1}-A_{2}}{2} \times Q_{P_{E}}
$$

Producer surplus:

$$
P S=\int_{0}^{Q_{E p}} p\left(Q_{D}\right) \mathrm{d} Q_{D}-\int_{0}^{Q_{E p}} p\left(Q_{S}\right) \mathrm{d} Q_{S}=\frac{A_{1}-A_{2}}{2} \times Q_{P_{E}}
$$

It assumes that utility demand $\left(D_{U}\right)$ and utility supply $\left(S_{U}\right)$ for a commodity are given under the following form.
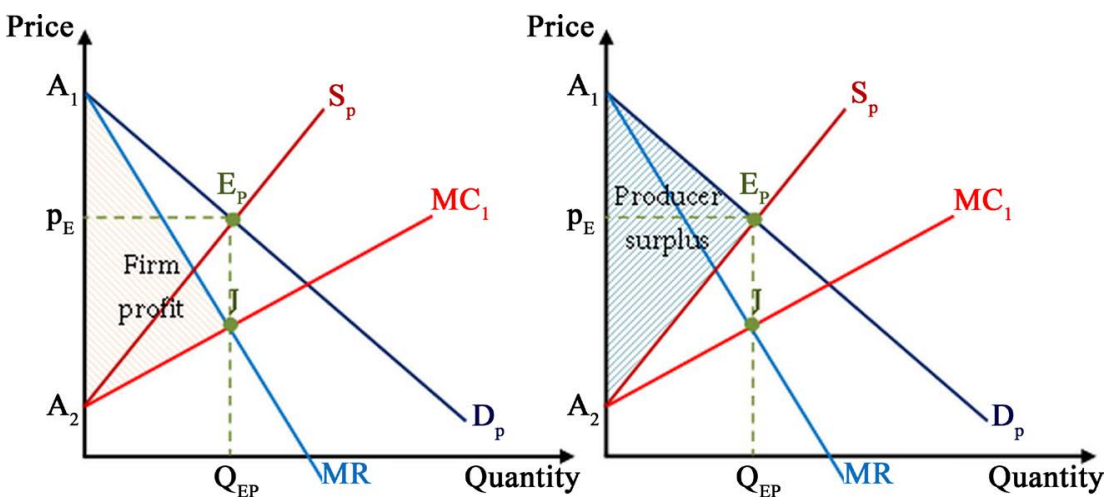

Figure 3. Firm profit and producer surplus. 
Utility demand:

$$
u=C_{1}+D_{1} \times Q_{D}
$$

Utility supply:

$$
u=C_{2}+D_{2} \times Q_{S}
$$

Marginal utility $(M U)$ and customer's marginal cost $\left(M C_{2}\right)$ are determined as follows:

Marginal utility:

$$
M U=C_{1}+2 D_{1} \times Q
$$

Customer's marginal cost:

$$
M C_{2}=C_{2}+\left(D_{1}+D_{2}\right) \times Q
$$

For utility-maximizing decision, the customer will consume at the quantity $\left(Q_{E u}\right)$ where marginal utility $(M U)$ equals the customer's marginal cost $\left(M C_{2}\right)$.

Utility's equilibrium quantity:

$$
Q_{E u}=\frac{C_{1}-C_{2}}{D_{2}-D_{1}}
$$

The utility-maximizing quantity is also the utility's equilibrium quantity $\left(Q_{E u}\right)$ in which the customer will buy at the equilibrium utility $\left(u_{E}\right)$ determined on the utility demand $\left(D_{U}\right)$, ceteris paribus.

Equilibrium utility:

$$
u_{E}=\frac{C_{1} \times D_{2}-C_{2} \times D_{1}}{D_{2}-D_{1}}
$$

Figure 4 shows the relationship between customer utility and customer surplus. Customer utility (the maximum value added to the customer) is the triangular area of $C_{1} K C_{2}$. This customer utility is exactly equal to customer surplus (the triangular area of $\left.C_{1} E_{u} C_{2}\right)$ whenever changes in utility demand $\left(D_{U}\right)$ or customer's marginal cost $\left(M C_{2}\right)$. Customer utility $(U)$ and customer surplus $(C S)$ are determined as follows:

Customer utility:

$$
U=\int_{0}^{Q_{E u}} M U \mathrm{~d} Q-\int_{0}^{Q_{E u}} M C_{2} \mathrm{~d} Q=\frac{C_{1}-C_{2}}{2} \times Q_{E u}
$$
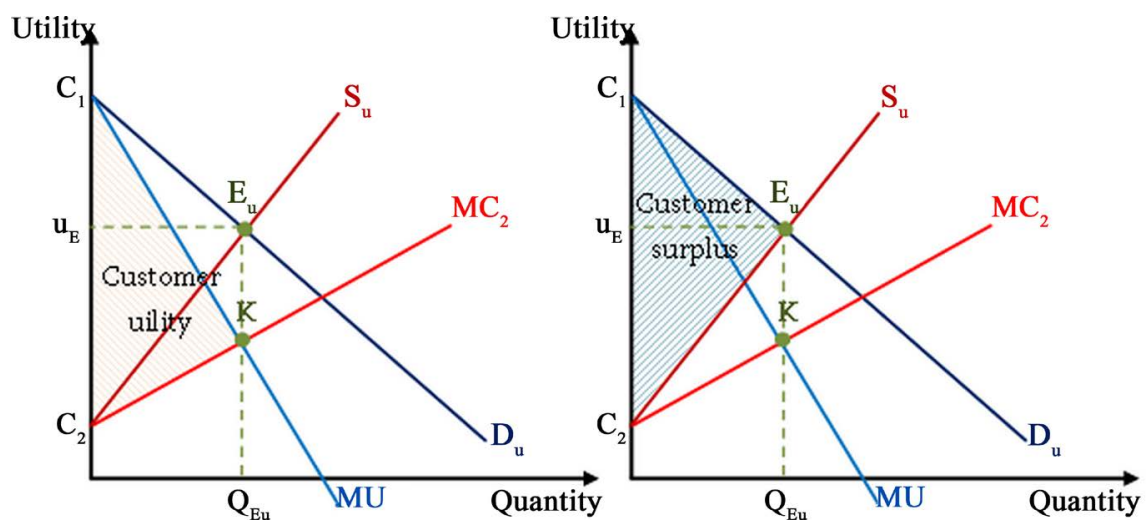

Figure 4. Customer utility and customer surplus. 
Customer surplus:

$$
C S=\int_{0}^{Q_{E u}} u\left(Q_{D}\right) \mathrm{d} Q_{D}-\int_{0}^{Q_{E u}} u\left(Q_{S}\right) \mathrm{d} Q_{S}=\frac{C_{1}-C_{2}}{2} \times Q_{E u}
$$

Value demand $\left(D_{V}\right)$ for a commodity is sum of price demand $\left(D_{P}\right)$ and utility demand $\left(D_{U}\right)$. Value supply $\left(S_{V}\right)$ for a commodity is sum of price supply $\left(S_{P}\right)$ and utility supply $\left(S_{U}\right)$.

Value demand:

$$
v=A_{1}+C_{1}+\left(B_{1}+D_{1}\right) \times Q_{D}
$$

Value supply:

$$
v=A_{2}+C_{2}+\left(B_{2}+D_{2}\right) \times Q_{S}
$$

Marginal value $(M V=M R+M U)$ and total marginal cost $\left(M C=M C_{1}+M C_{2}\right)$ are determined as follows:

Marginal value:

$$
M V=A_{1}+C_{1}+2\left(B_{1}+D_{1}\right) \times Q
$$

Total marginal cost:

$$
M C=A_{2}+C_{2}+\left(B_{1}+B_{2}+D_{1}+D_{2}\right) \times Q
$$

For value-maximizing decision, both the firm and the customer will produce and consume at the quantity $\left(Q_{E_{V}}\right)$ where marginal value $(M V)$ equals the total marginal cost $(M C)$.

Value's equilibrium quantity:

$$
Q_{E v}=\frac{A_{1}-A_{2}+C_{1}-C_{2}}{B_{2}-B_{1}+D_{2}-D_{1}}
$$

The value-maximizing quantity is also the value's equilibrium quantity $\left(Q_{E v}\right)$ in which the customer will receive at the equilibrium value $\left(V_{E}\right)$ determined on the value demand $\left(D_{V}\right)$, ceteris paribus.

Equilibrium value:

$$
v_{E}=\frac{\left(A_{1}+C_{1}\right) \times\left(B_{2}+D_{2}\right)-\left(A_{2}+C_{2}\right) \times\left(B_{1}+D_{1}\right)}{B_{2}-B_{1}+D_{2}-D_{1}}
$$

Figure 5 shows the relationship between net value and total surplus. Net value
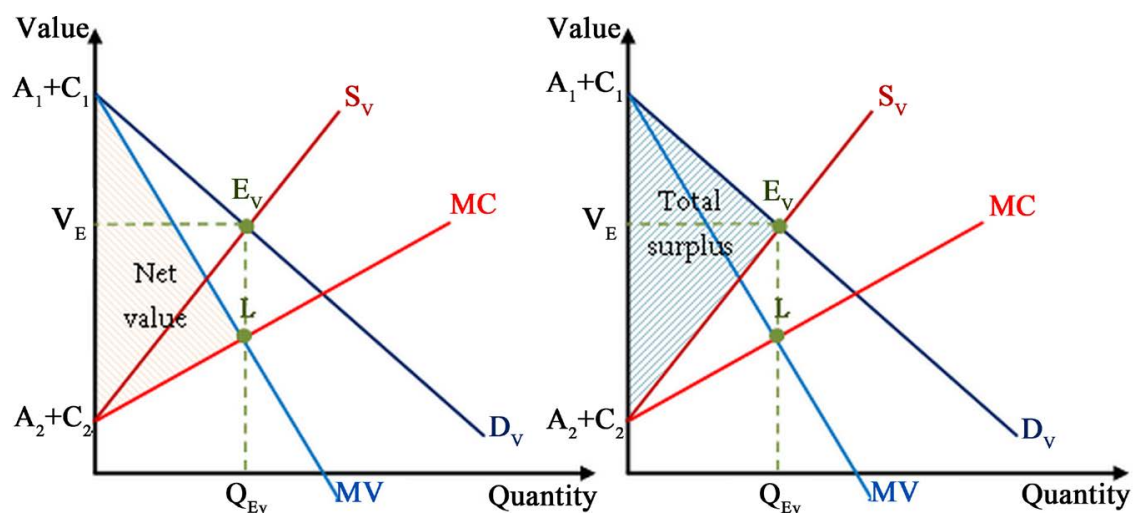

Figure 5. Net value and total surplus. 
(the maximum value added to both the firm and the customer) is a sum of firm profit and customer utility that is the triangular area of $\left(A_{1}+C_{1}\right) L\left(A_{2}+C_{2}\right)$. This net value is exactly equal to total surplus of producer surplus and customer surplus (the triangular area of $\left.\left(A_{1}+C_{1}\right) E_{V}\left(A_{2}+C_{2}\right)\right)$ whenever changes in value demand $\left(D_{V}\right)$ or total marginal cost $(M C)$. Net value $(V)$ and total surplus $(T S)$ are determined as follows:

Net value:

$$
V=\int_{0}^{Q_{E v}} M V \mathrm{~d} Q-\int_{0}^{Q_{E v}} M C \mathrm{~d} Q=\frac{\left(A_{1}+C_{1}\right)-\left(A_{2}+C_{2}\right)}{2} \times Q_{E v}
$$

Total surplus:

$$
T S=\int_{0}^{Q_{E v}} v\left(Q_{D}\right) \mathrm{d} Q_{D}-\int_{0}^{Q_{E v}} v\left(Q_{S}\right) \mathrm{d} Q_{S}=\frac{\left(A_{1}+C_{1}\right)-\left(A_{2}+C_{2}\right)}{2} \times Q_{E v}
$$

\section{Numerical Experiment}

In order to evaluate the value-maximizing behavior with the profit-maximizing behavior and the utility-maximizing behavior, a numerical experiment is carried out via a hypothetical value creation system with a single commodity, in which the production function and consumption function are assumed to be well-defined functions as in Table 1.

Demand function indicates relationship between value $(v)$ and price $(p)$ with their quantity demanded $\left(Q_{D}\right)$ given as follows:

Value demand:

$$
v=-\frac{3}{10} Q_{D}+29
$$

Price demand:

$$
p=-\frac{1}{5} Q_{D}+21
$$

Since value demand $\left(D_{V}\right)$ is a sum of price demand $\left(D_{P}\right)$ and utility demand $\left(D_{U}\right)$, utility demand is determined as follows:

Utility demand:

$$
u=v-p=-\frac{1}{10} Q_{D}+8
$$

Table 1. Parameters of the value creation system.

\begin{tabular}{ccccc}
\hline \multirow{2}{*}{ System Parameters } & \multicolumn{2}{c}{ Production } & \multicolumn{2}{c}{ Consumption } \\
\cline { 2 - 5 } & Symbol & Value & Symbol & Value \\
\hline Total factor productivity & $A 1$ & 1 & $A_{2}$ & 1 \\
Unit cost of capital & $w_{K 1}$ & 10 & $w_{K 2}$ & 3 \\
Unit cost of labor & $w_{L 1}$ & 3 & $w_{L 2}$ & 1 \\
Output elasticity of capital & $\alpha_{1}$ & 0.6 & $\alpha_{2}$ & 0.2 \\
Output elasticity of labor & $\beta_{1}$ & 0.4 & $\beta_{2}$ & 0.8 \\
\hline
\end{tabular}


Table 2 presents the experimental results for three maximizing behaviors. The profit-maximizing behavior provides the optimal solution at the quantity $\left(Q_{p}=\right.$ 22.23) for profit maximization $\left(\Pi_{M a x}=98.80\right)$, and the utility-maximizing behavior provides the optimal solution at the quantity $\left(Q_{\mathrm{u}}=29.73\right)$ for utility maximization ( $\left.U_{M a x}=88.37\right)$. The value-maximizing behavior provides the optimal solution at the quantity $\left(Q_{v}=24.73\right)$ for net value maximization $\left(V_{\operatorname{Max}}=\Pi+U=183.41\right)$, which provides the value balance between firm profit $(\Pi=97.55)$ and customer utility ( $U=85.86$ ). Since there exists a trade-off between the profit-maximizing behavior and the utility-maximizing behavior [25], the value-maximizing behavior provides optimal solution for a value balance between firm profit and customer utility that maximizes the net value as illustrated in Figure 6.

In order to illustrate market equilibrium for a commodity with given parameters of the value creation system as in Table 1, it requires to determine supply function that indicates relationship between value $(v)$ and price $(p)$ with their quantity supplied $\left(Q_{S}\right)$.

Table 2. Experimental results of the system.

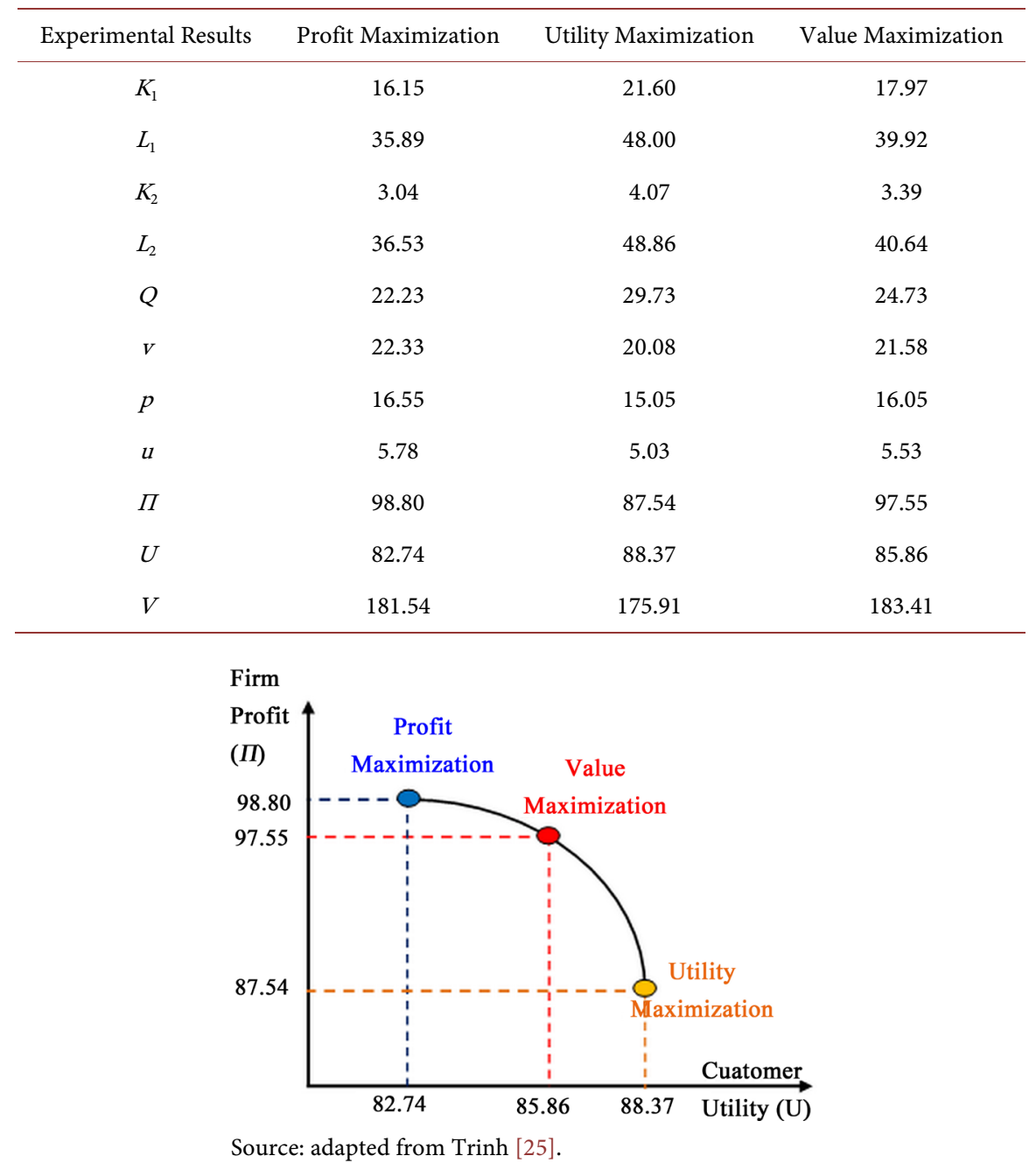

Figure 6. Maximizing behaviors and value balance. 
Marginal principle reveals that net benefit is maximum at the quantity where marginal benefit equals marginal cost. This optimal quantity is also equilibrium quantity where demand function intersects with supply function. The relationship between supply for a commodity and marginal cost are given as follows:

Price supply:

$$
p=M C_{1}-p^{\prime}\left(Q_{D}\right) \times Q_{S}
$$

Utility supply:

$$
u=M C_{2}-u^{\prime}\left(Q_{D}\right) \times Q_{S}
$$

Value supply:

$$
v=M C-v^{\prime}\left(Q_{D}\right) \times Q_{S}
$$

where $p^{\prime}\left(Q_{D}\right), u^{\prime}\left(Q_{D}\right)$, and $v^{\prime}\left(Q_{D}\right)$ are the first derivatives of price demand $(p)$, utility demand $(u)$, and value demand $(v)$, respectively.

Profit maximizing firm will produce at the quantity $\left(Q_{E p}\right)$ where marginal revenue $(M R)$ equals firm's marginal cost $\left(M C_{1}\right)$. This optimal quantity is also price's equilibrium quantity where price demand $\left(D_{P}\right)$ intersects with price supply $\left(S_{P}\right)$ as in Figure 7.

Total revenue:

$$
T R=p\left(Q_{D}\right) \times Q=\left(-\frac{1}{5} Q+21\right) \times Q=-\frac{1}{5} Q^{2}+21 \times Q
$$

Marginal revenue:

$$
M R=T R^{\prime}(Q)=-\frac{2}{5} Q+21
$$

Firm's total cost:

$$
T C_{1}=\left(\alpha_{1}+\beta_{1}\right) \times Q^{\frac{1}{\alpha_{1}+\beta_{1}}}\left[\left(w_{K_{1}}^{\alpha_{1}} \times w_{L_{1}}^{\beta_{1}}\right) /\left(A_{1} \times \alpha_{1}^{\alpha_{1}} \times \beta_{1}^{\beta_{1}}\right)\right]^{\frac{1}{\alpha_{1}+\beta_{1}}}=12.11 \times Q
$$

Firm's marginal cost:

$$
M C_{1}=T C_{1}^{\prime}(Q)=12.11
$$

Price supply:

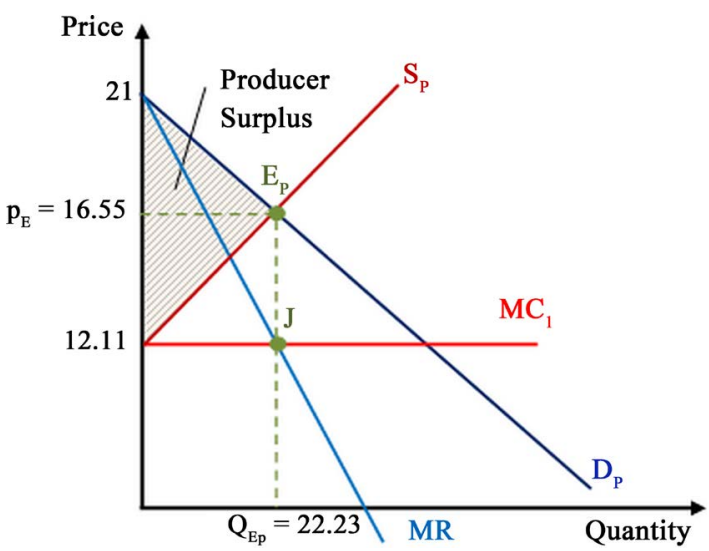

Figure 7. Price equilibrium and producer surplus. 


$$
p=M C_{1}-p^{\prime}\left(Q_{D}\right) \times Q_{S}=12.11+\frac{1}{5} Q_{S}
$$

Price's equilibrium quantity:

$$
M R=M C_{1} \Rightarrow Q_{E p}=22.23
$$

Firm profit $(\Pi)$ and producer surplus $(P S)$ are determined as follows:

$$
\begin{gathered}
\Pi=\int_{0}^{Q_{E p}} M R \mathrm{~d} Q-\int_{0}^{Q_{E p}} M C_{1} \mathrm{~d} Q=\left.\left(-\frac{1}{5} Q^{2}+8.89 \times Q\right)\right|_{0} ^{22.23}=98.80 \\
P S=\int_{0}^{Q_{E p}} p\left(Q_{D}\right) \mathrm{d} Q_{D}-\int_{0}^{Q_{E p}} p\left(Q_{S}\right) \mathrm{d} Q_{S}=\left.\left(-\frac{1}{5} Q^{2}+8.89 \times Q\right)\right|_{0} ^{22.23}=98.80
\end{gathered}
$$

Utility maximizing customer will consume at the quantity $\left(Q_{E u}\right)$ where marginal utility $(M U)$ equals customer's marginal cost $\left(M C_{2}\right)$. This optimal quantity is also utility's equilibrium quantity where utility demand $\left(D_{U}\right)$ intersects with utility supply $\left(S_{U}\right)$ as in Figure 8.

Total utility:

$$
T U=u\left(Q_{D}\right) \times Q=\left(-\frac{1}{10} Q+8\right) \times Q=-\frac{1}{10} Q^{2}+8 \times Q
$$

Marginal utility:

$$
M U=T U^{\prime}(Q)=-\frac{1}{5} Q+8
$$

Customer's total cost:

$$
T C_{2}=\left(\alpha_{2}+\beta_{2}\right) \times Q^{\frac{1}{\alpha_{2}+\beta_{2}}}\left[\left(w_{K_{2}}^{\alpha_{2}} \times w_{L_{2}}^{\beta_{2}}\right) /\left(A_{2} \times \alpha_{2}^{\alpha_{2}} \times \beta_{2}^{\beta_{2}}\right)\right]^{\frac{1}{\alpha_{2}+\beta_{2}}}=2.05 \times Q
$$

Customer's marginal cost:

$$
M C_{2}=T C_{2}^{\prime}(Q)=2.05
$$

Utility supply:

$$
u=M C_{2}-u^{\prime}\left(Q_{D}\right) \times Q_{S}=2.05+\frac{1}{10} Q_{S}
$$

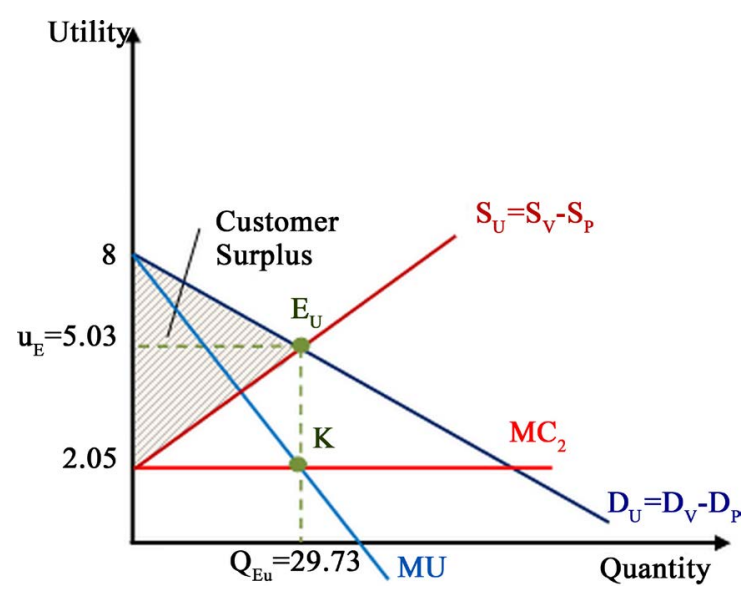

Figure 8. Utility equilibrium and customer surplus. 
Utility's equilibrium quantity:

$$
M U=M C_{2} \Rightarrow Q_{E u}=29.73
$$

Customer utility $(U)$ and customer surplus $(C S)$ are determined as follows:

$$
\begin{gathered}
U=\int_{0}^{Q_{E u}} M U \mathrm{~d} Q-\int_{0}^{Q_{E u}} M C_{2} \mathrm{~d} Q=\left.\left(-\frac{1}{10} Q^{2}+5.95 \times Q\right)\right|_{0} ^{29.73}=88.37 \\
C S=\int_{0}^{Q_{E u}} u\left(Q_{D}\right) \mathrm{d} Q_{D}-\int_{0}^{Q_{E u}} u\left(Q_{S}\right) \mathrm{d} Q_{S}=\left.\left(-\frac{1}{10} Q^{2}+5.95 \times Q\right)\right|_{0} ^{29.73}=88.37
\end{gathered}
$$

Value maximizing system will equilibrate at the quantity $\left(Q_{E V}\right)$ where marginal value $(M V)$ equals total marginal cost $\left(M C=M C_{1}+M C_{2}\right)$. This optimal quantity is also value's equilibrium quantity where value demand $\left(D_{V}\right)$ intersects with value supply $\left(S_{V}\right)$ as in Figure 9.

Total value:

$$
T V=v\left(Q_{D}\right) \times Q=\left(-\frac{3}{10} Q+29\right) \times Q=-\frac{3}{10} Q^{2}+29 \times Q
$$

Marginal value:

$$
M V=T V^{\prime}(Q)=-\frac{3}{5} Q+29
$$

Total cost:

$$
\begin{aligned}
T C= & \left(\alpha_{1}+\beta_{1}\right) \times Q^{\frac{1}{\alpha_{1}+\beta_{1}}}\left[\left(w_{K_{1}}^{\alpha_{1}} \times w_{L_{1}}^{\beta_{1}}\right) /\left(A_{1} \times \alpha_{1}^{\alpha_{1}} \times \beta_{1}^{\beta_{1}}\right)\right]^{\frac{1}{\alpha_{1}+\beta_{1}}} \\
& +\left(\alpha_{2}+\beta_{2}\right) \times Q^{\frac{1}{\alpha_{2}+\beta_{2}}}\left[\left(w_{K_{2}}^{\alpha_{2}} \times w_{L_{2}}^{\beta_{2}}\right) /\left(A_{2} \times \alpha_{2}^{\alpha_{2}} \times \beta_{2}^{\beta_{2}}\right)\right]^{\frac{1}{\alpha_{2}+\beta_{2}}} \\
= & T C_{1}+T C_{2}=14.16 \times Q
\end{aligned}
$$

Total marginal cost:

$$
M C=T C^{\prime}(Q)=14.16
$$

Value supply:

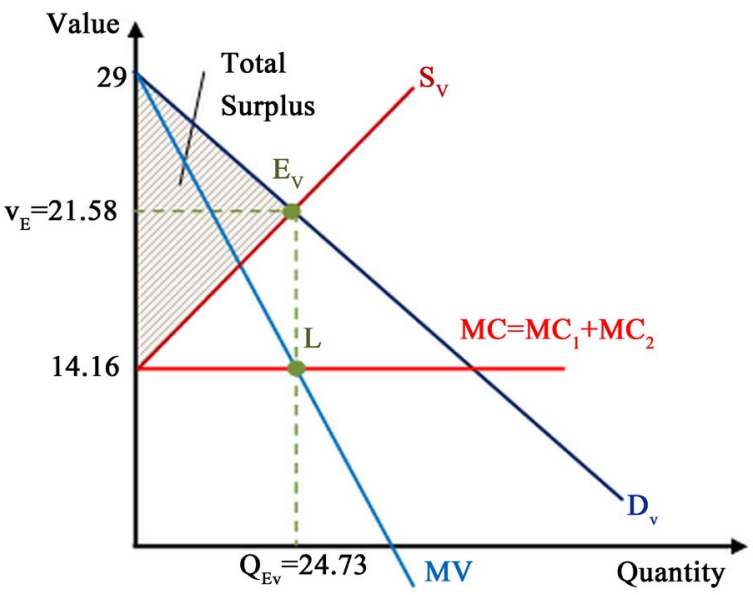

Figure 9. Value equilibrium and total surplus. 


$$
v=M C-v^{\prime}\left(Q_{D}\right) \times Q_{S}=14.16+\frac{3}{10} Q_{S}
$$

Value's equilibrium quantity:

$$
M V=M C \Rightarrow Q_{E v}=24.73
$$

Net value $(V)$ and total surplus (TS) are determined as follows:

$$
\begin{gathered}
V=\int_{0}^{Q_{E v}} M V \mathrm{~d} Q-\int_{0}^{Q_{E v}} M C \mathrm{~d} Q=\left.\left(-\frac{3}{10} Q^{2}+14.84 \times Q\right)\right|_{0} ^{24.73}=183.41 \\
T S=\int_{0}^{Q_{E v}} v\left(Q_{D}\right) \mathrm{d} Q_{D}-\int_{0}^{Q_{E v}} v\left(Q_{S}\right) \mathrm{d} Q_{S}=\left.\left(-\frac{3}{10} Q^{2}+14.84 \times Q\right)\right|_{0} ^{24.73}=183.41
\end{gathered}
$$

\section{Conclusions}

This paper explores the value concept and reformulates economic surplus that play an important role in explaining market behavior and economic welfare in today's society and economy. Economists not only want to understand how price for a commodity is determined, but also they also want to know how value for a commodity is created and distributed in the markets.

The theoretical models are developed to reformulate the concepts of economic surplus on the logic of maximizing behaviors in the market, in which these surplus concepts also provide an insightful explanation on the relationship between value added and economic welfare in the economy. The decision rule is used to identify the supply functions on the logic of maximizing behaviors in the market. The marginal principle and market equilibrium are important bases to reformulate the concepts of customer surplus and producer surplus. The numerical experiment is proposed for two-phase procedure. The first phase experiment is to conduct the value balance between firm profit and customer utility. The study result indicates that there exists the value balance between the firm and the customer. The value balance is also a necessary condition for market equilibrium that includes both price equilibrium and value equilibrium. The second phase experiment is to compute producer surplus and customer surplus. The study results indicate that 1) producer surplus is identified under price equilibrium, in which the producer surplus is measured upon the firms' profit-maximizing behavior; 2) customer surplus is identified under utility equilibrium, in which the customer surplus is measured upon the customers' utility-maximizing behavior.

The paper contributes to the development of value theory that provides a clear understanding of market behavior and welfare analysis in the economy. However, the paper has some limitations that also suggest for the further studies: 1) the supply function needs to consider under other forms of demand function; 2) endogeneity and exogeneity in market equilibrium should consider extending the logic of maximizing behaviors in the market.

\section{Conflicts of Interest}

The authors declare no conflicts of interest regarding the publication of this paper. 


\section{References}

[1] Smith, A. (1776) The Wealth of Nations. The Modern Library, New York.

[2] Ricardo, D. (1821) On the Principles of Political Economy and Taxation. John Murray, London.

[3] Marx, K. (1867) Capital Volume I. Foreign Languages Publishing House, Moscow.

[4] Bentham, J. (1789) An Introduction to the Principles of Morals and Legislation. Clarendon Press, Oxford. https://doi.org/10.1093/oseo/instance.00077240

[5] Dupuit, J. (1844) On the Measurement of the Utility of Public Works. International Economic Papers, 2, 83-110.

[6] Jevons, S.W. (1871) Theory of Political Economy. Macmillan, London.

[7] Menger, C. (1871) Principles of Economics. Braumüller, Germany.

[8] Marshall, A. (1890) Principles of Economics. Macmillan, London.

[9] Marx, K. (1959) A Contribution to the Critique of Political Economy. Progress Publishers, Moscow.

[10] Baran, P. and Sweezy, P. (1966) Monopoly Capitalism. An Essay on the American Economic and Social Order.

[11] Hicks, J.R. (1941) The Rehabilitation of Consumers' Surplus. The Review of Economic Studies, 8, 108-116. https://doi.org/10.2307/2967467

[12] Aristotle. (1959) Politics (4th century B.C.). Wm. Heinemann, London.

[13] Fleetwood, S. (1997) Aristotle in the 21st Century. Cambridge Journal of Economics, 21, 729-744. https://doi.org/10.1093/oxfordjournals.cje.a013695

[14] Wikström, S. (1996) The Customer as Co-Producer. European Journal of Marketing, 30, 6-19. https://doi.org/10.1108/03090569610118803

[15] Woodruff, R.B. and Gardial, S. (1996) Know Your Customers-New Approaches to Understanding Customer Value and Satisfaction. Blackwell Business, Cambridge, MA.

[16] Vargo, S.L. and Lusch, R.F. (2004) Evolving to a New Dominant Logic for Marketing. Journal of Marketing, 68, 1-17. https://doi.org/10.1509/jmkg.68.1.1.24036

[17] Grönroos, C. (2008) Service Logic Revisited: Who Creates Value? And Who Co-Creates? European Business Review, 20, 298-314. https://doi.org/10.1108/09555340810886585

[18] Grönroos, C. (2011) A Service Perspective on Business Relationships: The Value Creation, Interaction and Marketing Interface. Industrial Marketing Management, 40, 240-247. https://doi.org/10.1016/j.indmarman.2010.06.036

[19] Trinh, T.H. (2014) A New Approach to Market Equilibrium. International Journal of Economic Research, 11, 569-587.

[20] Trinh, T.H. (2018) Towards a Paradigm on the Value. Cogent Economics \& Finance, 6, Article ID: 1429094. https://doi.org/10.1080/23322039.2018.1429094

[21] Trinh, T.H., Kachitvichyanukul, V. and Khang, D.B. (2014) The Co-Production Approach to Service: A Theoretical Background. Journal of the Operational Research Society, 65, 161-168. https://doi.org/10.1057/jors.2012.183

[22] Grönroos, C. and Voima, P. (2012) Making Sense of Value and Value Co-Creation in Service Logic. Hanken School of Economics, Helsinki, Finland.

[23] Trinh, T.H. (2017) A primer on GDP and Economic Growth. International Journal of Economic Research, 14, 13-24. 
[24] Hicks, J.R. and Allen, R.G. (1934) A Reconsideration of the Theory of Value. Part I. Economica, 1, 52-76. https://doi.org/10.2307/2548574

[25] Trinh, T.H. (2017) Value Balance and General Equilibrium Model. International Journal of Economics of Financial Issues, 7, 485-491. 